\title{
Social Controller: Mobile-Based Application Solution for Social Networking Problems
}

\author{
Dr. Hassan Mustafa \\ Dean, College of Mass Communication, \\ Alfalah University, Dubai (UAE) \\ Dr. Mohanad Halaweh \\ Associate Professor, College of Mass Communication, \\ Alfalah University, Dubai (UAE)
}

\begin{abstract}
The excessive use of social networking applications (SNA) through smartphone devices has created many social problems. Long hours using SNA lead to isolation and loneliness, social anxiety, divorce, criminal activity, road accidents, violation of privacy, indirect interaction between family members and others, and health problems, including tension and depression. Societies throughout the world are facing these problems. Blocking SNA is obviously not the right solution. This paper presents a technical innovative solution that offers an acceptable remediation. The solution's business model, and features and capabilities which will ultimately have positive impacts on society, are demonstrated.
\end{abstract}

Keywords: Social Networking, Social Media, Mobile Application, Social Controller, Artificial Intelligence, Fake Information.

\section{Introduction}

According to Statista (2017), the number of smartphone users in the world is around 2.3 billion, and this number has been increased to 5 billion in 2018 according to the global digital report 2018 (digital report, 2018). Another global survey stated that half of the world's population (around 3.5 billion out of 7 billion people) is using smartphones (Hootsuite, 2017). The use of smartphones has become a ubiquitous and constant part of people's lives. Furthermore, a statistical survey (Hootsuite, 2017) showed that the total number of people using social media on their phones has increased over the years, to where almost $80 \%$ of all social media time is spent on smartphones using SNA (Facebook, Twitter, Snapchat, Instagram, etc.) (Marketing land, 2016). Studies have shown that the overuse of, and addiction to, SNA has resulted in social, ethical, criminal, and health problems (Conal \& Gary, 2017; Chia-che, 2016; David \& Perez, 2016; Hugues \& Hayley, 2015; Valenzuela, Halpern \& Katz, 2014). This paper presents a technical solution to these problems - a mobile application called a Social Controller. The application's purpose is to allow "Use but not Overuse, Misuse, or Abuse." Opportunities for and benefits of using SNA are many, and cannot be ignored or underestimated, so mobile users need to 'Use.' However, excessive use and addiction ('Overuse') may raise several types of problems either intentionally or without intension ('Misuse' or 'Abuse'). The principles, components, and features/functions of the Social Controller (App), and the business model, social benefit and implications of using the App are discussed. Additional to that the App expected to check the fake news and get verify them from the original resources using the Artificial Intelligence technology, so that users won't be fooled.

\section{Related Work and Social Controller App Solution}

In-depth research was conducted to determine if there were any available mobile applications for the purpose of controlling the usage of SNA. Applications were found that let the users know some statistics about their usage without putting it in a context to inform them of potential health and psychological impacts. Most of these applications are used mainly for blocking, monitoring, and tracking usage. There are many Apps that allow users to monitor the use of smartphone and SNA and stop addiction such as Moment, Space (Break Free), and off time (described in Table 1). However, the proposed solution, the Social Controller, is a new and unique application, 
has more features than monitoring and tracking, designed around the principles of awareness, interactivity, verification and participation. None of the above-mentioned applications were built based on these three principles.

\section{Awareness}

The proposed App will inform individuals of their usage of SNA (hours and minutes), and will provide information for health and psychological awareness, and customized tips and alerts whenever the time of usage reaches a critical level. That level can be set by the user or recommended by the application according to standard acceptable level. Also it verify some of news and information provided by social media pages and alert the user with specific notification and colors to avoid spending useless time on social media.

\section{Interactivity}

The App will provide the ability to connect with family members (spouse and children) or friend to monitor their hours of usage, and to send reminders when their usage time reaches a high level or a critical limit, with the possibility of stopping the usage. By constantly sending updates on social, cultural, and sports events, activities, and initiatives in a region close to the person, or in the country where $s /$ he resides, the App will encourage direct communication and interaction between individuals, instead of virtual and passive interactions through smartphones.

\section{Participation}

The aim of the App is to spread a culture of balanced use of SNA, to make family and community members (friends and acquaintances) closer and happier. The App will promote this culture through a feature that allows one user to challenge another user to spend less time on SNA for a specific period of time. Through the feature, the participants in the challenge will send each other reminders and alerts. They will be rewarded by a system where points are achieved based on declining hours of SNA usage. The challenge can be extended among family or group members. The App will participate in spreading the culture of balance through rewarding winners (received points cane be redeemed) with less time spent on SNA. Addition to that it also provide number of fake information which being explored by users and rewarding the less fake information number as well, so it will enhance the integrity and credibility values.

\section{Social Controller Components and Features/Functionality}

The features, functionality, and capability of the App were designed based on the three principles discussed above.

Table 1: Most used App for monitoring and tracking

\begin{tabular}{|c|c|}
\hline $\begin{array}{l}\text { Mobile } \\
\text { Application }\end{array}$ & Description/features/function (from the App's website ) \\
\hline Moment & $\begin{array}{l}\text { Moment is an iOS app that automatically tracks how much you use your iPhone and } \\
\text { iPad each day. If you're using your phone too much, you can set daily limits on } \\
\text { yourself and be notified when you go over. You can even force yourself off your device } \\
\text { when you're over your limit. Moment Family: Manage your family's screen time from } \\
\text { your own phone and set up time for your entire family to be screen-free using } \\
\text { family dinner time. }\end{array}$ \\
\hline $\begin{array}{l}\text { SPACE } \\
\text { formerly } \\
\text { (BreakFree) }\end{array}$ & $\begin{array}{l}\text { The app studies your phone usage pattern in the background and warns you with } \\
\text { timely notifications whenever you go overboard. the app calculates an addiction score } \\
\text { in real time and maintains a detailed history of your scores. The app also provides you } \\
\text { phone management tools such as disabling the internet, rejecting phone calls and } \\
\text { sending auto text messages. You can completely control your habits by scheduling } \\
\text { these tools to run on a given day at a given time. View usage stats for your top used } \\
\text { apps, call patterns and other functions to help you make informed decisions on taking } \\
\text { necessary actions. By installing it on your child's smartphone you can monitor his / } \\
\text { her phone usage, schedule internet hours. }\end{array}$ \\
\hline Offtime & $\begin{array}{l}\text { The OFFTIME app gives you space to breathe in our hyper-connected world. For set } \\
\text { periods of time of your choice, the service blocks disruptive notifications, calls or } \\
\text { SMS... Access to applications that tempt you is then restricted. Those who want to } \\
\text { learn more about their digital habits can also receive information about their } \\
\text { smartphone usage with the help of 'Insights.' (OFFTIME). }\end{array}$ \\
\hline
\end{tabular}




\section{Settings}

The settings section is where users will set their email, age, gender, country/city, SNA used, preferred level of usage (hours/minutes), and connected/associated users. These data will be used to provide customized information and messages to the users.

\section{Analytics}

The analytics section will track and analyze the time spent on SNA, the most-used SNA, time and date of usage, last usage, and accumulated points. Other option is related to verification by assigning a field for information to be checked from the original resources with the artificial intelligence method.

\section{Interactions}

The interactions section will be dynamic and constantly updated. It will provide the following: customized advice (e.g. health recommendation) based on the user's profile and level of usage; information about social events, activities, and initiatives that encourage face-to-face interaction with others as an alternative to passive interaction via smartphones; warnings of health effects of SNA usage; reminders from associated/connected users (for example, a mother alerting her son after observing his hours of usage); points awarded based on fewer hours or minutes of usage; honoring and rewarding users by APP (through annual event, announcement, points redeemed as gift from stores, organizations, etc.) who have had the least number of usage hours or the greatest decline in their usage, which is generated via analytics; enabling the user to challenge another member user to spend fewer hours/minutes on SNA (this can be set for 1 day or week or month), where the winner receives points which are transferred from the loser's account. These can also be redeemed annually. Also, users themselves can reward each other (father rewards his son).

Also the full fake information will be displayed in red color, gradually color changes till green color upon the number of fake information, especially after verification process, so points will be rewarding the greenest information being sending by user.

\section{Advertising}

Costs incurred by the development of the Social Controller and from the App participating in spreading the culture of balanced usage through rewarding the users must be covered. Expenses can be partially covered through paid advertising, which will appear as a pop-up message or a sign for new message. The ads and messages will be customized according to the user's profile. Advertising will cover some of the development costs, and will create a profit when a large database of users is established and companies will be interested in advertising through the App. Figure 1 shows an overview of the application.

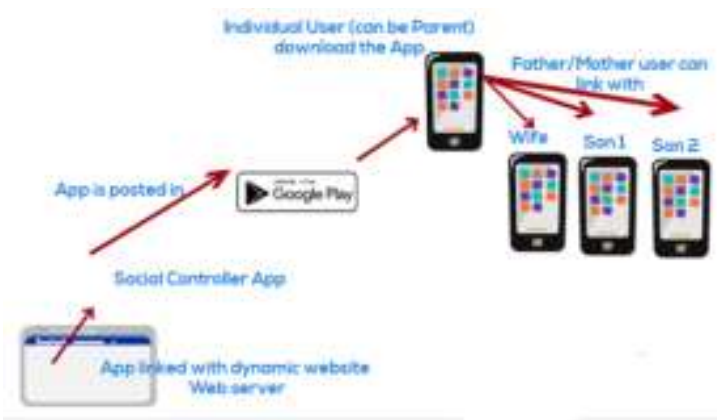

Figure 1: Social Controller App

\section{Business Model Analysis}

Business model describes the logic of how an organization creates, delivers and control value and how money are earned in a company (Osterwalder \& Pigneur (2010). Many tools were developed for planning and analyzing the business model. However, Osterwalder \& Pigneur (2010) developed the Business Model Canvas (BMC) which is one of the most famous framework used by academic, researchers and practitioners for this purpose (Weiller and Neely, 2013). The BMC was co-created by 470 practitioners from 45 countries. It is a powerful visual tool that clearly shows all the components of the business and their interconnections. The canvas consists of nine components (shown on Figure 2.) which are described in the following paragraphs. The BMC was operationalized for creating the Social Controller business model and presented in Table 2.

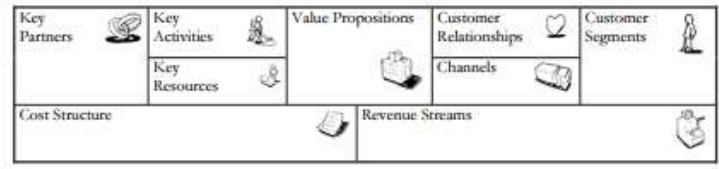

Figure 2 BMC by Osterwalder \& Pigneur (2010) 
1. The Value Propositions component describes the bundle of products and services that create value for a specific Customer Segment

2. The Customer Segments component defines the different groups of people or organizations an enterprise aims to reach and serve

3. The Channels component describes how a company communicates with and reaches its Customer Segments to deliver a Value Proposition

4. The Customer Relationships component describes the types of relationships a company establishes with specific Customer Segments
5. The Revenue Streams component represents the cash a company generates from each Customer Segment (costs must be subtracted from revenues to create earnings)

6. The Key Resources component describes the most important assets required to make a business model work

7. The Key Activities component describes the most important things a company must do to make its business model work

8. The Key Partnerships Building Block describes the network of suppliers and partners that make the business model work.

\section{Table 2: The Business Model Canvas}

\begin{tabular}{|c|c|c|c|c|}
\hline $\begin{array}{l}\text { Key Partners } \\
-\quad \text { XYZ } \\
\text { (removed) } \\
\text { which } \\
\text { provides the } \\
\text { fund/training } \\
\text { networking } \\
\text { and } \\
\text { consultations } \\
\text {-Google Play } \\
\text { \& Apple } \\
\text { Store which } \\
\text { provide the } \\
\text { platform for } \\
\text { publishing } \\
\text { the App } \\
\text {-Marketing } \\
\text { agencies or } \\
\text { Social media } \\
\text { applications } \\
\text { which will } \\
\text { put Ads for } \\
\text { the App. }\end{array}$ & $\begin{array}{l}\text { Key Activities } \\
\text {-Conduct thorough } \\
\text { research to evaluate } \\
\text { existing applications } \\
\text { available in the } \\
\text { market and then } \\
\text { define the unique } \\
\text { features/functions } \\
\text { of the Social } \\
\text { Controller. } \\
\text {-Specify the main } \\
\text { requirements of the } \\
\text { APP } \\
\text {-Develop the App } \\
\text { including two main } \\
\text { stages (initial } \\
\text { prototype including } \\
\text { the main functions, } \\
\text { stage two: second } \\
\text { prototype with } \\
\text { users testing and } \\
\text { feedback) and then } \\
\text { final release and } \\
\text { publication of the } \\
\text { application in } \\
\text { Google play/Apple } \\
\text { store. } \\
\text {-Create website for } \\
\text { the company } \\
\text {-Market } \\
\text { application in social } \\
\text { media and using } \\
\text { other marketing } \\
\text { channels }\end{array}$ & $\begin{array}{l}\text { Value Proposition } \\
\text { The Social Controller } \\
\text { App will give the user } \\
\text { ability to monitor and } \\
\text { control the amount of } \\
\text { time spent } \\
\text { (minutes/hours) on } \\
\text { social networking } \\
\text { applications (SNA) as } \\
\text { a result of the users' } \\
\text { awareness of negative } \\
\text { effects of SNA usage } \\
\text { (social, health ethical, } \\
\text { criminal problems } \\
\text { etc.), reward points, } \\
\text { and incentives. } \\
\text { The App will } \\
\text { encourage in } \\
\text { participation } \\
\text { interactive social } \\
\text { events and activities } \\
\text { (face-to-face), } \\
\text { connecting } \\
\text { challenging with other } \\
\text { users on less usage of } \\
\text { SNA, spreading the } \\
\text { culture of balanced } \\
\text { usage of SNA among } \\
\text { family members, } \\
\text { groups, and an an } \\
\text { communities in an } \\
\text { entertaining way } \\
\text { Thus, it helps in } \\
\text { reducing the social }\end{array}$ & $\begin{array}{l}\text { Customer } \\
\text { Relationships } \\
\text { The interactions } \\
\text { section of the App } \\
\text { will be dynamic and } \\
\text { constantly updated. } \\
\text { It will provide } \\
\text { customized advice } \\
\text { based on the user's } \\
\text { profile and level of } \\
\text { usage; information } \\
\text { about social } \\
\text { event/activities that } \\
\text { encourage face-to- } \\
\text { face interaction; } \\
\text { warnings of health } \\
\text { effects of SNA } \\
\text { usage; hor } \\
\text { honoring/rewarding } \\
\text { users by APP } \\
\text { (through annual } \\
\text { event, } \\
\text { announcement, } \\
\text { points redeemed as } \\
\text { gift from stores, etc.) } \\
\text { who have had the } \\
\text { least number of } \\
\text { usage hours or the } \\
\text { greatest decline in } \\
\text { their usage, which is } \\
\text { generated via } \\
\text { analytics; }\end{array}$ & $\begin{array}{l}\text { Customer } \\
\text { Segments } \\
\text {-Social } \\
\text { Media } \\
\text { smartphone } \\
\text { users } \\
\text {-Addicted } \\
\text { users to } \\
\text { social media } \\
\text { applications. } \\
\text {-Parents and } \\
\text { kids }\end{array}$ \\
\hline
\end{tabular}




\begin{tabular}{|c|c|c|c|}
\hline $\begin{array}{l}\text { Key Resources } \\
\text {-Expert educated keen founders } \\
\text {-Fund which will be obtained from } \\
\text { XYZ to cover the costs of software } \\
\text { development, marketing and others } \\
\text {-Startup Company registered in } \\
\text { Dubai (perfect place to startup the } \\
\text { business) }\end{array}$ & \multicolumn{2}{|c|}{$\begin{array}{l}\text { problems and makes } \\
\text { the family and society } \\
\text { closer and happier } \\
\text { App purpose is to } \\
\text { "Use but not Overuse, } \\
\text { Misuse or Abuse". }\end{array}$} & $\begin{array}{l}\text { Channels } \\
\text {-Publishing the App on Google Play } \\
\text { \& Apple Store } \\
\text {-Marketing on Social Media and } \\
\text { known websites } \\
\text { Email marketing for members/user } \\
\text { downloaded the free version of the } \\
\text { App } \\
\text {-International Forum/ Exhibitions }\end{array}$ \\
\hline \multicolumn{2}{|c|}{$\begin{array}{l}\text { Cost Structure } \\
\text {-Register new company in Dubai (registration } \\
\text { fees) } \\
\text {-Hire mobile programmer(s)/developers } \\
\text { /outsource or crowed-source (cost of App } \\
\text { development) } \\
\text {-Buying required software tools } \\
\text {-Create website and reserve domain for the } \\
\text { company } \\
\text {-Marketing the App in social media and other } \\
\text { marketing channels } \\
\text {-Other costs like utilities, office desk(s), } \\
\text { chairs, papers, laptop, and printer (Note: } \\
\text { these can be minimized as much possible } \\
\text { where unnecessary items will not be } \\
\text { purchased if they already available. } \\
\text {-Fees for publishing the App on Google } \\
\text { Play/Apple Store } \\
\text {-Costs for rewarding users }\end{array}$} & \multicolumn{2}{|c|}{$\begin{array}{l}\text { Revenue Streams } \\
\text { The business model depends on two sources of } \\
\text { revenue: } \\
\text {-Users who download the premium version } \\
\text {-Paid advertising: companies will advertise when a } \\
\text { large number of users has been established through } \\
\text { offering an option to download a free version of the } \\
\text { App (installed in one device without connecting } \\
\text { with other users, and with limited } \\
\text { analytics/features). A user who decides to download } \\
\text { the premium version will pay } \$ 1 \text { for the upgrade, } \\
\text { which will allow them to connect with other users } \\
\text { and get advanced analytics and more features. }\end{array}$} \\
\hline
\end{tabular}

The business model depends on two sources of revenue: users who download the premium version, and paid advertising. Companies will advertise when a large number of users has been established. Users will be gained through offering an option to download a free version of the App (installed in one device without connecting with other users, and with limited analytics and features). A user who decides to download the premium version will pay $\$ 1$ for the upgrade, which will allow them to connect with other users and get advanced analytics and more features.

The development of mobile applications can cost from $\$ 1,000$ to $\$ 100,000$, or even more, depending on many factors. One of the methods used to estimate the cost of mobile application software development is FunctionPoints, which determine the degree of software complexity. The degree of complexity depends on the number of interfaces/forms, input/output data, and number of functions/features in the application, whether it is linked with a dynamic database, and whether it is compatible with Apple (Apple Store) and Samsung platforms (Google Play).
The Social Controller will have a user-friendly interface, compatible with the Apple iOS platform and Google Play. It will require a login, and will have a profile section, connection with other users, linkage to the database server, analytics, an Advertisement control section, and reviews.

A web tool used to estimate the cost of creating the App that can be found at http://howmuchtomakeanapp.com/. The estimated maximum cost would be around $\$ 50,000$. The goal will be to reach all social media smart phone users in the world, and acquire 50,000 users in the first year. The break-even point will be reached when 50,000 users have downloaded the advanced version (paid $\$ 1$ each). This goal should not be difficult to reach, as the excessive use of social media is a global problem, common in many countries and societies. To reach a large number of users, marketing for the application will take place through different channels (internet marketing on social media/known websites, SMS and street boards). For Startup Company, the cost of marketing is estimated at maximum $20 \%$ of the targeted revenue. So, 
there will be additional marketing costs $(20 \%$ of $\$ 50000$ ) besides the cost of application development. The total estimated costs will be $\$ 60000$ so the number of targeted users in order to break-even becomes 60000 users. The above targeted revenue and number of users, and marketing budget are planned for one year time.

\section{Social Impact of the Social Controller}

The Social Controller application will provide a technical solution to track and control the use of SNA, thus reducing the related social problems and their economic consequences. It aims to spread a culture of balanced usage of SNA over the smartphone plus enhancing integrity by verification of information. The App, a new and unique application, will have a positive impact on society. It will provide user with the ability to control the amount of time spent on SNA (as a result of the users' awareness of negative effects of SNA usage, reward points, and incentives). In addition, the App will encourage participation in interactive social events and activities, spreading the culture of balanced usage of SNA among family members, groups, and communities in an entertaining way. Use of the App will lead to reduced bills associated with the excessive use of SNA. The App will provide added value to the community as it tackles social problems which have economic dimensions. The will help in reducing spread of fake information which may lead to political, health, economical problems as well.

The economic cost for the usage of SNA starts from the cost of the internet subscription (data package) for smartphones (4G). Smartphones are pervasive devices, used all the time and everywhere to access the internet. Greater usage means greater cost for the requested data package, although this cost has become relatively less nowadays in many countries.

A much greatest cost appears when, for instance, excessive use of SNA while driving causes a car accident that results in human and physical losses. There are also costs of treatment needed when excessive use of SNA causes psychological problems. Burglaries have resulted when people shared details of their lives. Others fall victim to cyberbullying and are forced to pay money. Marriages can be damaged resulting in divorce, which also has financial consequences. These are just a few of many examples. If the proposed App can spread the culture of balanced usage and reduce the usage time of SNA to an acceptable extent, all the above-mentioned problems will necessarily decline, and thus, the application will contribute to the betterment of society culturally, socially, and economically. The ultimate result will be that family and community members will become closer and happier. Thus the App will increase the knowledge awareness about the danger of fake information when spread among society, especially the information regarding the health issues which may cause death or fatal injuries. Also fake information may cause many damages in co-existing between communities.

\section{Conclusion}

Implementation of the Social Controller (Startup Company) will bring a creative idea to reality, and will present a new and unique solution to the overuse and abuse of SNA. The need for this solution is very significant, for the present and the future, because the number of SNA and the number of users will continue to increase, and the use of smartphone applications has become widespread. The App will be sustainable, and it will benefit future generations, as the majority of users of these applications are young. The proposed solution does not focus narrowly on specific users, categories of users, or a country. Rather, it encompasses everyone. The application has analytics (producing big data) which can offer many future business opportunities to provide new services. The App functions and features can also be extended.

One important implication of this application is that internet service providers (telecommunication companies) might not advocate its use, as it reduces usage of the internet and data packages. However, usage of the internet may remain the same without the overuse of SNA. Telecommunication companies also have a social responsibility toward the community in spreading the culture of balanced usage of SNA. Balanced usage is the aim of the Social Controller: "Use but not Overuse, Misuse, or Abuse."

\section{References}

- Conal T, Gary O. (2017). Associations of Self-Presentation on Facebook with Mental Health and Personality Variables: A 
Systematic Review. Cyberpsychology, Behavior, and Social Networking 20:10, 587-595.

- Chia-chen Y. (2016). Instagram Use, Loneliness, and Social Comparison Orientation: Interact and Browse on Social Media, But Don't Compare. Cyberpsychology, Behavior, and Social Networking,19, No. 12: 703-708

- David A B, Perez A G. (2016). The Relationship Between Online Social Networking and Depression: A Systematic Review of Quantitative Studies. Cyberpsychology, Behavior, and Social Networking, 19 11: 638-648.

- Global Digital Report 2018.

- https://digitalreport.wearesocial.com/

- Hugues, S. and Hayle, H. (2015). Use of Social Networking Sites and Risk of Cyberbullying Victimization: A Population-Level Study of Adolescents. Cyberpsychology, Behavior, and Social Networking, 18: 12, 704-710.

- Hootsuite, Digital in (2017). Global. https://wearesocial.com/specialreports/digital-in-2017-global-overview. Report from We Are Social and Hootsuite 2017

- Marketingland. Nearly 80 percent of social media time now spent on mobile devices. https:// marketingland.com/facebook- usage-accounts-1-5-minutes-spent-mobile171561

- Osterwalder, A. \& Pigneur, Y. (2010). Business Model Generation - A Handbook for Visionaires, Game Changers, and Challengers. New Jersey: John Wiley \& Sons, Inc

- Valenzuelaa S, Halperna D, Katzb J. (2014). Social network sites, marriage wellbeing and divorce: Survey and state-level evidence from the United States. Computers in Human Behavior,36, 94-101.

- Statista. Number of smartphone users worldwide from 2014 to 2020. 2017. https://www.statista.com/statistics/3306 95/number-of-smartphone-usersworldwide/

- Weiller, C. and Neely, A. (2013). Business Model Design in an Ecosystem Context; University of Cambridge: Cambridge, UK.

- Moment: https://inthemoment.io/ Accessed $2^{\text {nd }}$ December 2017

- Space: https://phonelifebalance.com/ Accessed $2^{\text {nd }}$ December 2017

- Offtime: http://offtime.co/ Accessed 2nd December 2017

- https://www.inc.com/jeremygoldman/6-apps-to-stop-yoursmartphone-addiction.html Accessed 2 ${ }^{\text {nd }}$ December 2017 